\title{
Functional and anatomical characterization of corticotropin-releasing factor receptor subtypes of the rat spinal cord involved in somatic pain relief
}

\section{Shaaban Mousa ( $\sim$ shaaban.mousa@charite.de)}

Charité- University Medical Center Department of Geriatrics and Retirement Medicine Benjamin Franklin Campus: Charite Universitatsmedizin Berlin Klinik fur Geriatrie und Altersmedizin Campus Benjamin Franklin https://orcid.org/0000-0002-2584-7422

\section{Mohammed Shaqura}

Charite Universitatsmedizin Berlin Campus Charite Mitte: Charite Universitatsmedizin Berlin

\section{Baled khalefa}

Charite Universitatsmedizin Berlin Campus Charite Mitte: Charite Universitatsmedizin Berlin

\section{Li Li}

Charité- University Medical Center Department of Geriatrics and Retirement Medicine Benjamin Franklin Campus: Charite Universitatsmedizin Berlin Klinik fur Geriatrie und Altersmedizin Campus Benjamin Franklin

\section{Mohammed Al-madol}

Charité- University Medical Center Department of Geriatrics and Retirement Medicine Benjamin Franklin Campus: Charite Universitatsmedizin Berlin Klinik fur Geriatrie und Altersmedizin Campus Benjamin Franklin

\section{Sascha Treskatsch}

Charité- University Medical Center Department of Geriatrics and Retirement Medicine Benjamin Franklin Campus: Charite Universitatsmedizin Berlin Klinik fur Geriatrie und Altersmedizin Campus Benjamin Franklin

\section{Michael Schäfer}

Charité- University Medical Center Department of Geriatrics and Retirement Medicine Benjamin Franklin Campus: Charite Universitatsmedizin Berlin Klinik fur Geriatrie und Altersmedizin Campus Benjamin Franklin

\section{Research Article}

Keywords: somatic pain, corticotropin-releasing factor, spinal cord, ENK-immunoreactive interneurons, immunoflourescence

Posted Date: March 19th, 2021 
DOI: https://doi.org/10.21203/rs.3.rs-268281/v3

License: (c) (1) This work is licensed under a Creative Commons Attribution 4.0 International License. Read Full License

Version of Record: A version of this preprint was published at Molecular Neurobiology on July 31st, 2021. See the published version at https://doi.org/10.1007/s12035-021-02481-z. 


\section{Abstract}

Corticotropin-releasing factor (CRF) orchestrates our body's response to stressful stimuli. Pain is often stressful and counterbalanced by activation of CRF receptors along the nociceptive pathway although the involvement of the CRF receptor subtypes 1 and/or 2 (CRF-R1 and CRF-R2, respectively) in CRF-induced analgesia remains controversial. This study examined CRF-R1 and CRF-R2 expression within the spinal cord of rats with Freund's complete adjuvant-induced hindpaw inflammation using reverse transcriptase polymerase chain reaction, Western blot, radioligand binding, and immunofluorescence confocal analysis. Moreover, paw pressure algesiometry examined antinociceptive effects of intrathecal (i.t.) CRF and their possible antagonism through CRF-R1 and/or CRF-R2 selective antagonists as well as the opioid receptor antagonist naloxone. Our results demonstrated predominantly CRF-R2 mRNA, protein, binding sites and immunoreactivity in the dorsal horn of the rat spinal cord. Consistently, CRF as well as CRF-R2 agonist elicited potent, dose-dependent anti-nociceptive effects which were antagonized selectively by i.t. CRF-R2 (K41498) antagonist but not by CRF-R1 (NBI35965) antagonist. Moreover, the opioid antagonist naloxone dose-dependently reversed the i.t. CRF- as well as CRF-R2 agonist-elicited inhibition of somatic pain. Supporting these findings, double immunofluorescence confocal microscopy showed CRF-R2 on enkephalin (ENK)-containing inhibitory interneurons in close opposition of incoming mu-opioid receptorimmunoreactive nociceptive neurons. CRF-R2 was, however, not seen on pre- or on postsynaptic sensory neurons of the spinal cord. Taken together, these findings suggest that i.t. CRF or CRF-R2 agonist inhibit inflammatory somatic pain, occurring predominantly through CRF-R2 receptors located on spinal enkephalinergic inhibitory interneurons, which results in endogenous opioid-mediated pain inhibition.

\section{Introduction}

Corticotropin-releasing factor (CRF) is a 41-amino-acid peptide which modulates endocrine, autonomic, and behavioral activity to orchestrate the body's response to acute and chronic stressful stimuli in order to maintain homeostasis [1]. Pain is such a stressful stimulus that triggers intrinsic compensatory mechanisms through activation of CRF receptors [2,3]. Since many of the physiological responses to stress can be reproduced by the administration of exogenous CRF, Hargreaves et al. [4] investigated for the first time in rats the potential antinociceptive effects of intravenously injected CRF. This showed a 5fold increase in endogenous ß-endorphin plasma levels and a significantly increased threshold to a $50{ }^{\circ} \mathrm{C}$ hot plate stimulus. Consistently, a randomized, double-blind placebo-controlled crossover study investigated the pain relief through i.v. injection of $100 \mu \mathrm{g}$ CRF in 14 patients undergoing third molar extraction. Injecting i.v. CRF 60 min after dental surgery led to a significantly reduced pain intensity and a two-fold increase in ß-endorphin plasma levels compared to placebo [4]. In contrast, testing the potential antinociceptive effects of i.v. $100 \mu \mathrm{g} C R F$ to heat stimuli in 18 healthy volunteers $[5,6]$, following a double-blind, cross-over and placebo-controlled design, failed to show any effect, most likely due to the lack of persistent ongoing pain.

In addition to somatic pain, CRF seems to intervene in the regulation of visceral pain [7]. Indeed, intracerebroventricular administration of CRF resulted in a significant inhibition of the nociceptive 
visceromotor response to colorectal distension [8]. Moreover, systemic application of a CRF-R2 agonist inhibited an increase in the spinal activity marker ERK1/2 and prevented a nociceptive visceromotor response to colorectal distension [9]. However, previous studies suggest that CRF-R1 and CRF-R2 activation may have opposing roles in the regulation of visceral pain [7] and the net result of CRF receptor activation may depend on whether the receptors are localized in the brain [10], spinal cord [9], peripheral tissues [7] or immune cells [11]. A growing body of evidence suggests a close link between the pathological condition of the irritable bowel syndrome and the CRF system [12]. Moreover, the accumulating data from the clinical trials confirmed the regulatory role of CRF in pain control of patients with visceral pain [13], postoperative joint pain [14], and fibromyalgia [15, 16].

Our previous studies showed the involvement of spinal CRF receptors in somatic pain modulation through endogenous opioid peptides [17]. However, the biological activities of CRF in various pathophysiological conditions are circumstantial and remain controversial [18]. This diverse effect may be due to the different types of CRF receptors. Indeed, the effects of CRF is mediated by two distinct membrane receptors, the CRF-R1 and CRF-R2, which differ in their anatomical distribution and pharmacological characteristics $[19,20]$. Therefore, the main goal of the present study was to determine the CRF-R1 and CRF-R2 distribution in the rat spinal cord and to investigate contribution of spinal CRF-R1 and/or CRF-R2 to the modulation of inflammatory pain.

\section{Materials And Methods}

\section{Animals}

Experiments were conducted in male Wistar rats (200-250 g) (Charité-Universitätsmedizin Berlin, Campus Benjamin Franklin, Berlin, Germany). Rats were housed individually in cages and maintained on a $12 \mathrm{~h}$ light/dark schedule with food pellets and water ad libitum. Room temperature was maintained at $22 \pm 0.5^{\circ} \mathrm{C}$ and at a relative humidity between 60 and $65 \%$. Experiments and animal care were performed according to the European Directive (2010/63/EU) introducing new animal welfare and care guidelines and were approved by the local animal care committee of the Senate of Berlin, Germany (Landesamt für Arbeitsschutz, Gesundheitsschutz und Technische Sicherheit, Berlin). All efforts were made to minimize the number of animals used and their suffering.

\section{Induction of inflammation}

Under brief anesthesia with isoflurane (Willy Rüsch $\mathrm{GmbH}$, Böblingen, Germany), rats received an intraplantar (i.pl.) injection of $0.15 \mathrm{ml} \mathrm{FCA} \mathrm{into} \mathrm{the} \mathrm{right} \mathrm{hind} \mathrm{paw.} \mathrm{This} \mathrm{treatment} \mathrm{consistently} \mathrm{produces} \mathrm{a}$ localized inflammation of the inoculated paw as reflected with an increase in paw volume, paw temperature and infiltration with various types of immune cells as previously described by [21].

\section{Surgery to implant i.t catheter}


The intrathecal catheterization (i.t) was performed as previously described [22, 23]. Briefly, an incision was made at the L3-L4 level. The catheter was inserted through needle at the L4-L5 vertebra. Keeping the angle of the needle parallel with the dorsal surface, the catheter was carefully pushed upward to reach L4 at the lumbar enlargement. The needle was carefully removed and the catheter was sealed with glue to the tissue to secure it. Then, saline was injected intrathecally in a volume of $10 \mu$ to flush the catheter. Another skin incision was made at the neck of the animal and the catheter was tunnelled under the skin and pulled out at the neck after which incisions were sutured. Animals showing signs of neurological damage were immediately excluded from the study. The intrathecal location of the catheter was confirmed by administration of $10 \mu \mathrm{l}$ of lidocaine $2 \%$ flushed with $10 \mu \mathrm{l}$ of saline. Lidocaine but not saline caused reversible bilateral hindlimb paresis. The animals were allowed 2 days to recover. Drugs were injected intrathecally in a volume of $10 \mu \mathrm{l}$ followed by $10 \mu \mathrm{l}$ of vehicle to flush the catheter. All rats were investigated for correct catheter position in relation to the spinal cord on post-mortem laminectomy.

\section{Drugs}

The following drugs were used: rat/human CRF (Sigma-Aldrich, St. Louis, MO); CRF-R2 agonist urocortin2 (Ucn-2), CRF-R2 antagonist K41498; CRF-R1 antagonist NBI35965 (Bio-Techne GmbH, WiesbadenNordenstadt, Germany). Doses were calculated as the free base and drugs were dissolved in isotonic saline as vehicle. Volume of i.t. drug administration was $(10 \mu \mathrm{l})$. For each dose a separate group of animals $(n=6)$ was used. Drugs were administered during brief isoflurane anesthesia.

\section{CRF-R1 and CRF-R2 mRNA detection by conventional PCR}

PCR analysis for CRF-R1 and CRF-R2 specific mRNA from rat dorsal root ganglia was performed as described previously [24]. Total RNA was extracted from L3-5 dorsal root ganglia of Wistar rats ( $n=5$ per experimental group) using RNeasy Kit (Qiagen, Hilden, Germany). 0,5 $\mu$ ( $25 \mathrm{pmol}$ ) oligo dT and $2 \mu \mathrm{l}$ (200pmol) random primers were added up to $1 \mu \mathrm{g}$ total RNA, incubated at $37^{\circ} \mathrm{C}$ for $15 \mathrm{~min}$, then at $85^{\circ} \mathrm{C}$ for $5 \mathrm{sec}$, finally at $4^{\circ} \mathrm{C}$ for transfer onto ice (according to TaKaRa ${ }^{\circledR}$ manual). cDNA was stored at $-20^{\circ} \mathrm{C}$. The following specific primers were used: for CRF-R1, forward primer: ACACTACCATGTTGCAGTC, reverse primer: GAACATCCAGAAG AAGTTGG (EnsembI, Accession Nr: NM_030999); for CRF-R2, forward primer: CACACTGTGAACCCATTT TGG, reverse primer: GATGAGTTGCAGCAGG (Ensembl, Accession NM_022714). Conventional PCR was performed with a Maxima Hotstart Green Enzyme kit (Thermo Fisher Scientific GmbH Berlin, Germany). Amplification was carried on an Eppendorf PCR-Cycler Vapo.Protect (Eppendorf Vertrieb Deutschland $\mathrm{GmbH}$, Wesseling-Berzdorf) out for 40 cycles, each consisting of $30 \mathrm{sec}$ at $95^{\circ} \mathrm{C}$ and of $30 \mathrm{sec}$ at $60^{\circ} \mathrm{C}$ and $30 \mathrm{sec}$ at $72^{\circ} \mathrm{C}$. Specific bands were visualised on $2 \%$ agarose gel plus $0.01 \%$ ethidium bromide; the entire PCR product of $20 \mu \mathrm{l}$ migrated for $40 \mathrm{~min}$ at 100 $V$ in the BioRad chamber system with 1x TAE buffer. The imaging was performed on a Gel Doc EZ Imager (Bio-Rad Laboratories GmbH, Feldkirchen, Germany).

\section{Radioligand Binding Assay}


The following experiments should identify CRF1 or CRF2 specific binding sites in membrane preparations of rat spinal cord similar to our previous binding studies $[25,26]$. Membrane preparations from Wistar rat atria were prepared by homogenizing them in cold assay buffer ( $50 \mathrm{mM}$ Tris-HCl, 1 mM EGTA, $5 \mathrm{mM}$ $\mathrm{MgCl}_{2}, \mathrm{pH}$ 7.4) and were centrifuged at $48,000 \times \mathrm{g}$ at $4^{\circ} \mathrm{C}$ for $20 \mathrm{~min}$. The pellet was resuspended in assay buffer followed by $10 \mathrm{~min}$ incubation at $37^{\circ} \mathrm{C}$ to remove endogenous ligands. The homogenates were centrifuged again and resuspended in assay buffer. Membranes were aliquoted and stored at $-80^{\circ} \mathrm{C}[26]$.

Displacement binding experiments were performed using [125]-iodinated CRF (Specific Activity $1.0 \mathrm{nmol}$, PerkinElmer, Germany). $200 \mu \mathrm{g}$ of membrane protein was incubated with [125]-iodinated CRF (1.0 $\mu \mathrm{mol})$ displaced with $10^{-13}-10^{-5} \mathrm{M}$ of CRF-R2 antagonist K41498 or CRF-R1 antagonist NBI35965 for $1 \mathrm{~h}$ at $22^{\circ} \mathrm{C}$ in a total volume of $1 \mathrm{ml}$ of binding buffer ( $50 \mathrm{mM}$ Tris-HCl, $5 \mathrm{mM}$ EDTA, $5 \mathrm{mM} \mathrm{MgCl} 2,100 \mathrm{mM}$ $\mathrm{NaCl}, 0.2 \%$ bovine serum albumin). Nonspecific binding was defined as radioactivity remaining bound in the presence of $10 \mu \mathrm{M}$ unlabeled CRF. At the end of the incubation period, bound and free ligands were separated by rapid filtration over GF/C filters under vacuum using a Brandel cell harvester (Gaithersburg, MD, USA). Filters were washed three times with $4 \mathrm{ml}$ of cold buffer ( $50 \mathrm{mM}$ Tris- $\mathrm{HCl}, \mathrm{pH}$ 7.4). Bound radioactivity was determined by liquid scintillation spectrophotometry after overnight extraction of the filters in $3 \mathrm{ml}$ of scintillation fluid [26]. All experiments were performed in duplicate and carried out at least four times. Nonspecific binding was subtracted from all [125]-iodinated CRF data. IC50 values in saturation binding assays were determined by nonlinear regression analysis of concentration-effect curves using GraphPad Prism (GraphPad Software Inc., CA, USA).

\section{Algesiometric testing}

Nociceptive thresholds were assessed by paw pressure test (modified Randall-Selitto test). Animals ( $\mathrm{n}=6$ per group) were gently restrained under paper wadding and incremental pressure was applied via a wedge-shaped, blunt piston onto the dorsal surface of the hind paw by means of an automated gauge (Ugo Basile). The pressure required to elicit paw withdrawal, the paw-pressure threshold (PPT), was determined. A cutoff of $250 \mathrm{~g}$ was used. Three consecutive trials, separated by intervals of $10 \mathrm{~s}$, were conducted and the average was determined. Baseline PPT were tested before and 4 days after inoculation with FCA. The same procedure was performed on the contralateral side; the sequence of sides was alternated between subjects to preclude order effects. In all behavioral experiments, drugs were prepared by a different person (M. Sh.) and the examiners (B.N. and L.L.) were unaware of the treatment that each animal received by chance.

\section{Western blot}

Spinal cord from adult rats were solubilized and extracted for immunoblotting investigations as previously described [27]. Briefly, the samples were homogenized in boiling SDS sample buffer (100 mM Tris, 2\% SDS, 20\% glycerol). The protein concentration was measured using a BCA assay (Pierce, Rockford, IL, USA). 2-Mercaptoethanol and bromophenol blue were added before loading. The extracts were separated using SDS-PAGE $(10 \%)$ using $80 \mu \mathrm{g}$ protein per lane and then transferred onto 
nitrocellulose filters. The filters were blocked in $2.5 \%$ milk for $1 \mathrm{~h}$ and incubated with rabbit polyclonal CRF-R1 antibody raised against synthetic 17 amino acid peptide from $\mathrm{N}$-Terminus extracellular domain of CRF-R1 (MBL, Wobum, MA, USA; MC-1778) or rabbit polyclonal CRF-R2 antibody raised against synthetic peptide corresponding to the extracellular N-terminal domain of CRF-R2 (Sigma; St Louis, MO, USA, C4241) $\left(1: 2.000\right.$, in $2.5 \%$ milk) overnight at $4^{\circ} \mathrm{C}$. After incubation with the secondary antibody (peroxidase-conjugated goat anti-rabbit, 1:40,000, Jackson ImmunoResearch, West Grove, PA) for $2 \mathrm{~h}$ at ambient temperature, reactive protein bands were digitally visualized using ECL solutions (SuperSignal West Pico, Thermo Scientific) in ChemiDoc MP Imager. Finally, the blots were reprobed with monoclonal mouse anti-GAPDH antibody (1:20,000; Sigma Aldrich) as an internal standard. Experiments were performed in groups of 4 animals.

The Western blot bands specific for CRF-R1 (56 kDa) or CRF-R2 (38 kDa) according to their data sheet were quantified by Java Image processing and analysis software (ImageJ, open-source image software downloaded from the web\# $[28,29]$.

\section{Receptor selectivity}

The most effective dose of i.t. CRF was administered together with different doses of CRF-R2 antagonist $\mathrm{K} 41498(0.75,1.5,3,5 \mathrm{nmol})$ or CRF-R1 antagonist NBI35965 $(0,0.001,0.002,0.004 \mathrm{nmol})$ to determine the receptor selectivity of CRF-mediated antinociceptive effects. Then, the most effective dose of i.t. CRFR2 antagonist urocortin II ( $0.78 \mathrm{pmol})$ was administered alone or together with different doses of corresponding CRF-R2 antagonist K41498 $(0.75,1.5,3,5 \mathrm{nmol})$ to determine the receptor selectivity of CRF2-mediated antinociceptive effects.

To examine whether CRF-elicited antinociception is opioid-mediated, the most effective doses of i.t. CRF agonist $(0.002 \mathrm{nmol})$ or CRF-R2 agonist Ucn-2 $(0.75 \mathrm{pmol})$ were administered together with the opioid receptor antagonist naloxone $(0.05,1,3 \mathrm{mg})$.

\section{Immunohistochemistry}

\section{Tissue preparation}

Four days after FCA inoculation, rats were deeply anesthetized with isoflurane and transcardially perfused with $100 \mathrm{ml}$ warm saline, followed by $300 \mathrm{ml} 4 \%$ (w/v) paraformaldehyde in $0.16 \mathrm{M}$ phosphate buffer solution ( $\mathrm{pH}$ 7.4). After perfusion, spinal cord (L4-5) and brain were removed, postfixed in the same fixatives for 90 min, and then cryoprotected overnight at $4^{\circ} \mathrm{C}$ in PBS containing $10 \%$ sucrose. The tissues were then embedded in tissue-Tek compound (OCT, Miles Inc. Elkhart, IN) and frozen. Spinal cord and brain were serially cut at $40 \mu \mathrm{m}$ on cryostat. Every fourth section of spinal cord and brain was collected in PBS (floating sections).

\section{Immunofluorescence staining}


For single or double immunofluorescence, tissue sections were processed as described previously [17]. Briefly, coronal or parasagittal spinal cord and brain sections were incubated with rabbit polyclonal antibody against CRF-R1 or CRF-R2 alone or in combination with guinea pig polyclonal antibody against CGRP (1:1000, Peninsula Laboratories, Belmont, CA), mouse monoclonal antibody against ENK (1:1000) or guinea pig polyclonal antibody against MOR (1:1000, Chemicon International, MA) as well as with guinea pig polyclonal antibody against CGRP in combination with rabbit anti-rat MOR (dilution of 1:1000) overnight at $4 \mathrm{C}^{\circ}$. After incubation with primary antibodies, the tissue sections were washed with PBS and then incubated with Texas Red conjugated goat anti-rabbit antibody (Vector Laboratories) in combination with Alexa Fluor 488 goat anti-guinea pig or anti-mouse antibody (Invitrogen, Germany). Thereafter, sections were washed with PBS, and the nuclei stained bright blue with 4'-6-Diamidino-2-phenylindole (DAPI) $(0.1 \mu \mathrm{g} / \mathrm{ml}$ in PBS) (Sigma). Finally, the tissues were washed in PBS, mounted in vectashield (Vector Laboratories) and imaged on a confocal laser scanning microscope, LSM510 (Carl Zeiss, Göttingen, Germany). To demonstrate specificity of staining, the following controls were included as mentioned in detail elsewhere [17, 19, 30,31]: (i) pre-absorption of diluted antibody against ENK, MOR with a synthetic peptide for ENK (Peninsula laboratories) or MOR (Gramsch Laboratories), respectively. (2) omission of either the primary antisera or the secondary antibodies.

\section{Analysis of data}

Data were analysed using one-way ANOVA followed Dunnett's post hoc test. For data not normally distributed, Kruskal-Wallis One Way Analysis of Variance on ranks was performed, followed by Dunnett's or Tukey post hoc test. Dose-response curves were analyzed by one-way ANOVA followed by linear regression. Differences were considered significant if $P<0.05$. All tests were performed using Sigma Stat 2.03 (SPSS Science, Chicago, IL) software. Data are expressed as means \pm SD or means \pm s.e.m.

\section{Results}

\section{Distinct expression of spinal CRF-R1 and CRF-R2 receptors}

Using a highly specific primer pair, both CRF-R1 and CRF-R2 mRNA were detectable in the dorsal part of the spinal cord (Fig. 1a). Concurrently, protein precipitation and separation of the dorsal part of the spinal cord (L4-L5) via gel electrophoresis and subsequent western blot revealed prominent CRF-R2 protein bands at the expected molecular weight ( $38 \mathrm{kDa}$ ), whereas CRF-R1 protein bands (56 kDa) were only faintly detectable (Fig. 1b).

Consistent with these findings, displacement experiments of radiolabeled [125 J]-CRF-binding by CRF-R1(NBI35965) and CRF-R2- (K41498) selective antagonists in membranes of the dorsal part of the spinal cord demonstrated clearly identifiable displacement with increasing concentrations of the CRF-R2selective antagonist K41498 $\left(\mathrm{IC}_{50}=500 \mathrm{pmol}\right)(\mathrm{Fig} .1 \mathrm{C})$ yet a lack of displacement with the CRF-R1 selective antagonist NBI35965 (Fig. 1c). 
In cross-sectional spinal L4-L5 segments of naïve rats CRF-R2 immunoreactivity was strongly visible, whereas CRF-R1 immunoreactivity was only scarce (Fig. 2). CRF-R2 immunoreactivity was predominantly detectable in Rexed laminae I and II on both sides of the spinal dorsal horn (Fig. 2a) and in the immediate vicinity of the central canal (Fig. 2b), an area receiving descending projections from supraspinal nuclei [32], whereas CRF-R1 immuno-reactivity was not detectable in Rexed laminae I and II (Fig. 2d) and was only scarce around the central canal (Fig. 2e). CRF-R1 (Fig. 2f) as well as CRF-R2 (Fig. 2c) immunoreactivity, however, were clearly detectable in brain areas of known CRF-R1 expression such as hypothalamus confirming the specificity of the antibody $[33,34]$.

\section{Distinct contribution of CRF-R2 and CRF-R1 receptors to the antinociceptive effects of intrathecal CRF in inflamed hindpaws}

In Wistar rats with local hindpaw inflammation, i.t administration of increasing doses of CRF significantly and dose-dependently increased paw pressure thresholds (PPT), $P<0.001$, one-way ANOVA and post-hoc Dunnett's test) (Fig. 3a). This anti-nociceptive effect of i.t CRF was antagonized with increasing i.t doses of the CRF-R2 receptor selective antagonist K41498 $(P<0.001$, one-way ANOVA and post-hoc Dunnett's test) (Fig. 3b), but with the CRF-R1 receptor selective antagonist NBI35965 ( $P>0.05$, one-way ANOVA) (Fig. 3c).

To corroborate this finding, animals with hindpaw inflammation received the CRF-R2 selective agonist Ucn-2 intrathecally which also resulted in dose-dependent increased paw pressure thresholds $(P<0.001$, one-way ANOVA and post-hoc Dunnett's test) (Fig. 4a). As expected, this anti-nociceptive effect of i.t Ucn2 was antagonized by increasing i.t doses of the CRF-R2 receptor selective antagonist K41498 $(P<0.001$, one-way ANOVA and post-hoc Dunnett's test) confirming CRF-R2 receptor selectivity (Fig. 4b).

Intriguingly, i.t administration of either CRF (Fig. 5a) or Ucn-2 (Fig. 5b) together with the opioid receptor antagonist naloxone dose-dependently diminished the anti-hyperalgesic effect of both substances $(P<$ 0.001, one-way ANOVA and post-hoc Dunnett's test) indicating an opioid receptor-mediated effect.

\section{Spinal cord areas of CRF receptor and opioid peptide co-expression}

CRF-R2 immunoreactivity was found in the dorsal horn, the parasympathetic nucleus, and around the central canal of the spinal cord (Fig. 6). Double immunofluorescence confocal microscopy showed that CRF-R2 immunoreactivity within superficial laminae of the spinal dorsal horn predominantly overlapped with ENK-immunoreactivity (Fig. 7). Since most ENK-IR neurons within the dorsal horn characterize inhibitory interneurons [35-37], our results suggest that CRF-R2 was mainly expressed in inhibitory enkepalinergic interneurons of the dorsal horn of the spinal cord (Fig. 7). These ENK-ir spinal interneurons were found in close proximity of MOR derived from incoming CGRP-ir sensory neurons (Fig. 8).

\section{Discussion}


Extending our previous observations that i.t CRF significantly diminishes mechanical hyperalgesia in rat inflamed hindpaws [17], the present study identified CRF-R2 as the most prominent CRFreceptor subtype within rat spinal cord which are densely localized in Rexed laminae I and II of the dorsal horn, whereas the CRF-R1 receptors are scarce. Consistently, spinal receptor binding of I-125 radiolabeled CRF was fully displaced by the CRF-R2- but not by the CRF-R1-selective antagonist. Our behavioral experiments in rats with FCA-induced hindpaw inflammation showed that i.t CRF-induced antinociceptive effects were fully antagonized by the CRF-R2 (K41498) but not by the CRF-R1 (NBI35965) selective antagonist. The same antinociceptive effect was obtained by i.t injection of the CRF-R2 selective agonist Ucn-2 confirming a predominant involvement of spinal CRF-R2. Interestingly, CRF-R2-mediated antinociceptive effects were reversible by the opioid antagonist naloxone indicating the involvement of endogenous opioid peptides. Indeed, double immunofluorescence confocal microscopy of the spinal cord showed a dense colocalization of CRF-R2 with ENK-containing interneurons in close opposition of corresponding MOR from incoming sensory neurons. Together, these findings suggest that CRF-R2 located on spinal enkephalinergic inhibitory interneurons are the most prominent CRF-receptor subtype involved in endogenous opioid-mediated inflammatory pain inhibition.

Spinal cord isolation of poly-A-tail mRNA and conventional reversetranscriptase PCR with primers specific for CRF-R2 and CRF-R1 revealed nucleotide bands of the expected sizes confirming the expression of both receptors in the lumbar part of the spinal cord. While Sosanya et al. [38] also demonstrated abundant CRF-R2 mRNA in the spinal cord of Sprague Dawley rats, they were unable to detect CRF-R1 mRNA. CRF-R2 mRNA was also confirmed in the rat spinal cord by reversetranscriptase-polymerase chain reaction [9], while [39] Korosi et al. reported the presence of both CRF-R1 and CRF-R2 mRNA in the mouse spinal cord using in-situ hybridization. In our Western blot experiments the respective protein bands for both receptors were detectable at their expected molecular weight, however, the protein band for CRF-R2 was much more prominent, while that for CRF-R1 was only weakly detectable, indicating a considerably higher density of spinal CRF-R2 than CRF-R1 receptors. A very low expression of spinal CRF-R1 - as indicated by the western blot results - could be an explanation for why in our radiolabeled ligand binding experiments spinal [ $\left.{ }^{125} \mathrm{~J}\right]$-CRF binding sites were fully displaced by the selective CRF-R2 ligand (K41498) but not by the selective CRF-R1 ligand (NBI35965). Our results extend previous autoradiographic CRF receptor studies in the rat spinal cord $[40,41]$ demonstrating a predominance of CRF-R2 over CRF-R1 binding cites. Consistently, immunofluorescence staining of rat spinal cord showed that CRF-R2 was mainly distributed in the superficial laminae of the dorsal horn, whereas CRF-R1 immunoreactivity was only scarcely distributed throughout the spinal cord, confirming previous autoradiographic studies [41]. Taken together, our findings of CRF-R2 receptor protein and membrane binding sites strongly support the notion that CRF-R2 is the dominant CRF receptor subtype in rat spinal cord.

Extending our previous findings [17], the present behavioral experiments revealed that i.t CRF-induced anti-nociception was dose-dependently attenuated by the selective CRF-R2 (K41498) but not by the CRFR1 (NBI35965) antagonist. Consistently, i.t application of the CRF-R2 agonist Ucn-2 dose-dependently and receptor-specifically reduced the inflammation-evoked nociception. Originally, Hargreaves et al. [4] 
demonstrated for the first time that i.v. CRF elicited an antinociceptive effect in rats similar to that of morphine. In a clinical trial, dental surgery patients having received i.v. CRF 60 min after third molar extraction exhibited significantly less postoperative pain compared to placebo [4]. A central role of CRF in nociceptive behavior was further supported by Lariviere et al. [18, 42], particularly under stressful conditions. In addition, more recent studies supported the role of spinal CRF-R2 in visceral pain [38, 9, 43]. Consistently, colorectal distension-induced ERK1/2-phosphorylation in dorsal horn neurons of spinal laminae I and II was attenuated by the CRF-R2 agonist Ucn-2 [9].

In line with our previous study [17], i.t application of the opioid receptor antagonist naloxone reversed the antinociceptive effects of CRF. Extending these findings, our present behavioral experiments showed that the anti-nociceptive effect of i.t. CRF-R2-selective agonist Ucn-2 was attenuated by naloxone. This suggests that anti-nociception of i.t. CRF or CRF-R2 agonist Ucn-2 seems to be mediated by activation of opioid receptors through endogenous opioid peptides within the spinal cord. In line with our behavioral findings, our double immunofluorescence confocal microscopy analysis showed that most of CRF2-IR nerve fibers overlap with ENK-IR interneurons but not with primary afferent (CGRP-IR) central endings or MOR-ir nociceptive neurons in the superficial dorsal horn of the spinal cord. Consistent with a release of opioid peptides, our results show that the ENK positive inhibitory interneurons are in close proximity of clusters of MOR-IR nociceptive neurons located on incoming CGRP-ir nociceptive neurons [44] and their activation may contribute to presynaptic-inhibition of sensory neuron neurotransmitter release $[45,46]$ and/or postsynaptic hyperpolarization of excitatory neurons ([47].

\section{Conclusion}

In summary, the current study demonstrates that the intrathecal application of CRF or the CRF-R2 agonist Ucn-2 elicits potent anti-nociception in an animal model of persistent inflammatory pain. This effect is dose-dependent and attenuated by the CRF-R2 (K41498) but not by the CRF-R1 (NBI35965) selective antagonist, indicating CRF-R2 receptor selectivity. Moreover, i.t. opioid receptor antagonist naloxone dosedependently reversed either CRF's or CRF-R2 agonist's antinociceptive effects at the spinal level of pain transmission. Consistently, we have identified ENK-immunoreactive inhibitory interneurons which coexpress CRF-R2 within the dorsal horn of the spinal cord. The present results highlight the need for further clinical studies to investigate the pain modulatory role of CRF-R2 that is mediated by spinal endogenous opioids during inflammatory pain.

\section{Abbreviations}

CRF: corticotropin releasing factor; CRF receptors subtypes 1: CRF-R1; CRF receptors subtypes 2: CRF-R2; ENK: enkephalin; FCA: Freund's complete adjuvant; i.t.: intrathecal; PPT: paw pressure thresholds; DRG: dorsal root ganglia; PCR: polymerase chain reaction.

\section{Declarations}




\section{Research Funding:}

Not applicable

\section{Conflicts of interest/Competing interests:}

The authors declare no potential conflicts of interest with respect to the research, authorship, and/or publication of this article.

\section{Availability of data and materials:}

The datasets used and/or analyzed during the current study are available from the corresponding author (Shaaban.mousa@charite.de) on reasonable request. The authors will take responsible for maintaining availability.

\section{Code availability:}

Not applicable

\section{Compliance with ethical standards:}

All animal experiments were approved by the local animal care committee (Landesamt für Gesundheit und Soziales, LaGeSo Berlin) and according to the European Directive (2010/63/EU) introducing new animal welfare and care guideline.

\section{Consent for publication:}

Not applicable

\section{Authors' contributions:}

SM, MoSh, BN, and MS designed the experiments; SM, MoSh, BN, MA and LL performed the experiments; SM, MoSh, LL, MA, ST, and MS performed the analyses and interpretation of the experiments; SM, MoSh, LL, MA and MS wrote part of the manuscript and all authors critically reviewed the manuscript.

\section{Acknowledgments}

We thank Mrs. Petra von Kwiatkowski (Technician, Berlin, Germany) for her technical assistance and Dr. Giulia Schäfer for language editing.

\section{References}

1. Bale TL, Vale WW (2004) CRF and CRF receptors: role in stress responsivity and other behaviors. Annu Rev Pharmacol Toxicol 44:525-557. doi:10.1146/annurev.pharmtox.44.101802.121410 
2. Larauche M (2012) Novel insights in the role of peripheral corticotropin-releasing factor and mast cells in stress-induced visceral hypersensitivity. Neurogastroenterology motility: the official journal of the European Gastrointestinal Motility Society 24(3):201-205. doi:10.1111/j.13652982.2011.01867.x

3. Yarushkina NI, Bagaeva TR, Filaretova LP (2011) Central corticotropin-releasing factor (CRF) may attenuate somatic pain sensitivity through involvement of glucocorticoids. Journal of physiology pharmacology: an official journal of the Polish Physiological Society 62(5):541-548

4. Hargreaves KM, Mueller GP, Dubner R, Goldstein D, Dionne RA (1987) Corticotropin-releasing factor (CRF) produces analgesia in humans and rats. Brain research 422(1):154-157. doi:10.1016/00068993(87)90550-6

5. Matejec R, Uhlich H, Hotz C, Mühling J, Harbach HW, Bödeker RH, Hempelmann G, Teschemacher H (2005) Corticotropin-releasing hormone reduces pressure pain sensitivity in humans without involvement of beta-endorphin(1-31), but does not reduce heat pain sensitivity. Neuroendocrinology 82(3-4):185-197. doi:10.1159/000091980

6. Lautenbacher S, Roscher S, Kohl G, Vedder H, Krieg J (1999) Corticotropin-releasing-hormone lacks analgesic properties: an experimental study in humans, using non-inflammatory pain. Pain 83(1):17. doi:10.1016/s0304-3959(99)00072-x

7. Nozu T, Takakusaki K, Okumura T (2014) A balance theory of peripheral corticotropin-releasing factor receptor type 1 and type 2 signaling to induce colonic contractions and visceral hyperalgesia in rats. Endocrinology 155(12):4655-4664. doi:10.1210/en.2014-1421

8. Larauche M, Moussaoui N, Biraud M, Bae WK, Duboc H, Million M, Taché Y (2019) Brain corticotropin-releasing factor signaling: Involvement in acute stress-induced visceral analgesia in male rats. Neurogastroenterology motility: the official journal of the European Gastrointestinal Motility Society 31(2):e13489. doi:10.1111/nmo.13489

9. Million M, Wang L, Wang Y, Adelson DW, Yuan PQ, Maillot C, Coutinho SV, McRoberts JA, Bayati A, Mattsson H, Wu V, Wei JY, Rivier J, Vale W, Mayer EA, Taché Y (2006) CRF2 receptor activation prevents colorectal distension induced visceral pain and spinal ERK1/2 phosphorylation in rats. Gut 55(2):172-181. doi:10.1136/gut.2004.051391

10. Taché Y (2015) Corticotrophin-releasing factor 1 activation in the central amygdale and visceral hyperalgesia. Neurogastroenterology motility: the official journal of the European Gastrointestinal Motility Society 27(1):1-6. doi:10.1111/nmo.12495

11. Chatoo M, Li Y, Ma Z, Coote J, Du J, Chen X (2018) Involvement of Corticotropin-Releasing Factor and Receptors in Immune Cells in Irritable Bowel Syndrome. Front Endocrinol 9:21. doi:10.3389/fendo.2018.00021

12. Nozu T, Okumura T (2015) Corticotropin-releasing factor receptor type 1 and type 2 interaction in irritable bowel syndrome. Journal of gastroenterology 50(8):819-830. doi:10.1007/s00535-015$1086-8$ 
13. Nozu T, Kudaira M (2006) Corticotropin-releasing factor induces rectal hypersensitivity after repetitive painful rectal distention in healthy humans. Journal of gastroenterology 41(8):740-744. doi:10.1007/s00535-006-1848-4

14. Likar R, Mousa SA, Steinkellner H, Koppert W, Philippitsch G, Stein C, Schäfer M (2007) Involvement of intra-articular corticotropin-releasing hormone in postoperative pain modulation. Clin J Pain 23(2):136-142. doi:10.1097/01.ajp.0000210954.93878.0d

15. McLean SA, Williams DA, Stein PK, Harris RE, Lyden AK, Whalen G, Park KM, Liberzon I, Sen A, Gracely RH, Baraniuk JN, Clauw DJ (2006) Cerebrospinal fluid corticotropin-releasing factor concentration is associated with pain but not fatigue symptoms in patients with fibromyalgia. Neuropsychopharmacology: official publication of the American College of Neuropsychopharmacology 31(12):2776-2782. doi:10.1038/sj.npp.1301200

16. Lund I, Lundeberg T, Carleson J, Sönnerfors H, Uhrlin B, Svensson E (2006) Corticotropin releasing factor in urine-a possible biochemical marker of fibromyalgia. Responses to massage and guided relaxation. Neurosci Lett 403(1-2):166-171. doi:10.1016/j.neulet.2006.04.038

17. Mousa SA, Bopaiah CP, Richter JF, Yamdeu RS, Schäfer M (2007) Inhibition of inflammatory pain by CRF at peripheral, spinal and supraspinal sites: involvement of areas coexpressing CRF receptors and opioid peptides. Neuropsychopharmacology: official publication of the American College of Neuropsychopharmacology 32(12):2530-2542. doi:10.1038/sj.npp.1301393

18. Lariviere WR, Melzack R (2000) The role of corticotropin-releasing factor in pain and analgesia. Pain 84(1):1-12. doi:10.1016/s0304-3959(99)00193-1

19. Mousa SA, Bopaiah CP, Stein C, Schäfer M (2003) Involvement of corticotropin-releasing hormone receptor subtypes 1 and 2 in peripheral opioid-mediated inhibition of inflammatory pain. Pain 106(3):297-307. doi:10.1016/s0304-3959(03)00302-6

20. Turnbull AV, Rivier C (1997) Corticotropin-releasing factor (CRF) and endocrine responses to stress: CRF receptors, binding protein, and related peptides. Proceedings of the Society for Experimental Biology and Medicine Society for Experimental Biology and Medicine (New York, NY) 215 (1):1-10. doi:10.3181/00379727-215-44108

21. Rittner HL, Brack A, Machelska H, Mousa SA, Bauer M, Schäfer M, Stein C (2001) Opioid peptideexpressing leukocytes: identification, recruitment, and simultaneously increasing inhibition of inflammatory pain. Anesthesiology 95(2):500-508. doi:10.1097/00000542-200108000-00036

22. Schmitt TK, Mousa SA, Brack A, Schmidt DK, Rittner HL, Welte M, Schäfer M, Stein C (2003) Modulation of peripheral endogenous opioid analgesia by central afferent blockade. Anesthesiology 98(1):195-202. doi:10.1097/00000542-200301000-00030

23. Størkson RV, Kjørsvik A, Tjølsen A, Hole K (1996) Lumbar catheterization of the spinal subarachnoid space in the rat. J Neurosci Methods 65(2):167-172. doi:10.1016/0165-0270(95)00164-6

24. Li X, Shaqura M, Mohamed D, Beyer A, Yamada S, Mousa SA, Schafer M (2018) Pro- versus Antinociceptive Nongenomic Effects of Neuronal Mineralocorticoid versus Glucocorticoid Receptors 
during Rat Hind Paw Inflammation. Anesthesiology 128(4):796-809.

doi:10.1097/aln.0000000000002087

25. Shaqura MA, Zöllner C, Mousa SA, Stein C, Schäfer M (2004) Characterization of mu opioid receptor binding and $\mathrm{G}$ protein coupling in rat hypothalamus, spinal cord, and primary afferent neurons during inflammatory pain. J Pharmacol Exp Ther 308(2):712-718. doi:10.1124/jpet.103.057257

26. Zollner C, Shaqura MA, Bopaiah CP, Mousa S, Stein C, Schafer M (2003) Painful inflammationinduced increase in mu-opioid receptor binding and G-protein coupling in primary afferent neurons. Mol Pharmacol 64(2):202-210. doi:10.1124/mol.64.2.202

27. Mohamed DM, Shaqura M, Li X, Shakibaei M, Beyer A, Treskatsch S, Schäfer M, Mousa SA (2020) Aldosterone Synthase in Peripheral Sensory Neurons Contributes to Mechanical Hypersensitivity during Local Inflammation in Rats. Anesthesiology 132(4):867-880.

doi:10.1097/aln.0000000000003127

28. Shaqura M, Li L, Mohamed DM, Li X, Treskatsch S, Buhrmann C, Shakibaei M, Beyer A, Mousa SA, Schäfer M (2020) Neuronal aldosterone elicits a distinct genomic response in pain signaling molecules contributing to inflammatory pain. J Neuroinflamm 17(1):183. doi:10.1186/s12974-02001864-8

29. Shaqura M, Li X, Al-Khrasani M, Shakibaei M, Tafelski S, Furst S, Beyer A, Kawata M, Schafer M, Mousa SA (2016) Membrane-bound glucocorticoid receptors on distinct nociceptive neurons as potential targets for pain control through rapid non-genomic effects. Neuropharmacology 111:1-13. doi:10.1016/j.neuropharm.2016.08.019

30. Mousa SA, Shakibaei M, Sitte N, Schafer M, Stein C (2004) Subcellular pathways of beta-endorphin synthesis, processing, and release from immunocytes in inflammatory pain. Endocrinology 145(3):1331-1341. doi:10.1210/en.2003-1287

31. Brack A, Rittner HL, Machelska H, Shaqura M, Mousa SA, Labuz D, Zollner C, Schafer M, Stein C (2004) Endogenous peripheral antinociception in early inflammation is not limited by the number of opioid-containing leukocytes but by opioid receptor expression. Pain 108(1-2):67-75. doi:10.1016/j.pain.2003.12.008

32. Ohashi N, Ohashi M, Baba H (2019) Action of Norepinephrine on Lamina X of the Spinal Cord. Neuroscience 408:214-225. doi:10.1016/j.neuroscience.2019.04.004

33. Tan LA, Vaughan JM, Perrin MH, Rivier JE, Sawchenko PE (2017) Distribution of corticotropinreleasing factor (CRF) receptor binding in the mouse brain using a new, high-affinity radioligand, [(125) I]-PD-Sauvagine. J Comp Neurol 525(18):3840-3864. doi:10.1002/cne.24307

34. Primus RJ, Yevich E, Baltazar C, Gallager DW (1997) Autoradiographic localization of CRF1 and CRF2 binding sites in adult rat brain. Neuropsychopharmacology: official publication of the American College of Neuropsychopharmacology 17(5):308-316. doi:10.1016/s0893-133x(97)00071-7

35. Millan MJ (1999) The induction of pain: an integrative review. Progress in neurobiology 57(1):1-164. doi:10.1016/s0301-0082(98)00048-3 
36. Schulte G, Robertson B, Fredholm BB, DeLander GE, Shortland P, Molander C (2003) Distribution of antinociceptive adenosine $\mathrm{A} 1$ receptors in the spinal cord dorsal horn, and relationship to primary afferents and neuronal subpopulations. Neuroscience 121(4):907-916. doi:10.1016/s03064522(03)00480-9

37. Llewellyn-Smith IJ, Dicarlo SE, Collins HL, Keast JR (2005) Enkephalin-immunoreactive interneurons extensively innervate sympathetic preganglionic neurons regulating the pelvic viscera. J Comp Neurol 488(3):278-289. doi:10.1002/cne.20552

38. Sosanya NM, Trevino AV, Chavez RL, Christy RJ, Cheppudira BP (2017) Sound-stress-induced altered nociceptive behaviors are associated with increased spinal CRFR2 gene expression in a rat model of burn injury. Journal of pain research 10:2135-2145. doi:10.2147/jpr.S144055

39. Korosi A, Kozicz T, Richter J, Veening JG, Olivier B, Roubos EW (2007) Corticotropin-releasing factor, urocortin 1, and their receptors in the mouse spinal cord. J Comp Neurol 502(6):973-989. doi:10.1002/cne.21347

40. Skofitsch G, Insel TR, Jacobowitz DM (1985) Binding sites for corticotropin releasing factor in sensory areas of the rat hindbrain and spinal cord. Brain research bulletin 15(5):519-522. doi:10.1016/0361-9230(85)90043-7

41. De Souza EB (1995) Corticotropin-releasing factor receptors: physiology, pharmacology, biochemistry and role in central nervous system and immune disorders. Psychoneuroendocrinology 20(8):789819. doi:10.1016/0306-4530(95)00011-9

42. Lariviere WR, Fiorenzani P, Ceccarelli I, Massafra C, Sorda G, Di Canio C, Aloisi AM (2011) Central $\mathrm{CRH}$ administration changes formalin pain responses in male and female rats. Brain research 1383:128-134. doi:10.1016/j.brainres.2011.01.106

43. Nijsen M, Ongenae N, Meulemans A, Coulie B (2005) Divergent role for CRF1 and CRF2 receptors in the modulation of visceral pain. Neurogastroenterology motility: the official journal of the European Gastrointestinal Motility Society 17(3):423-432. doi:10.1111/j.1365-2982.2005.00644.x

44. Arvidsson U, Riedl M, Chakrabarti S, Lee JH, Nakano AH, Dado RJ, Loh HH, Law PY, Wessendorf MW, Elde R (1995) Distribution and targeting of a mu-opioid receptor (MOR1) in brain and spinal cord. The Journal of neuroscience: the official journal of the Society for Neuroscience 15(5 Pt 1):33283341. doi:10.1523/jneurosci.15-05-03328.1995

45. Honsek SD, Seal RP, Sandkühler J (2015) Presynaptic inhibition of optogenetically identified VGluT3 + sensory fibres by opioids and baclofen. Pain 156(2):243-251. doi:10.1097/01.j.pain.0000460304.63948.40

46. Heinke B, Gingl E, Sandkühler J (2011) Multiple targets of $\mu$-opioid receptor-mediated presynaptic inhibition at primary afferent $A \delta$ - and C-fibers. The Journal of neuroscience: the official journal of the Society for Neuroscience 31(4):1313-1322. doi:10.1523/jneurosci.4060-10.2011

47. Trafton JA, Abbadie C, Marek K, Basbaum Al (2000) Postsynaptic signaling via the [mu]-opioid receptor: responses of dorsal horn neurons to exogenous opioids and noxious stimulation. The 
Journal of neuroscience: the official journal of the Society for Neuroscience 20(23):8578-8584. doi:10.1523/jneurosci.20-23-08578.2000

\section{Figures}
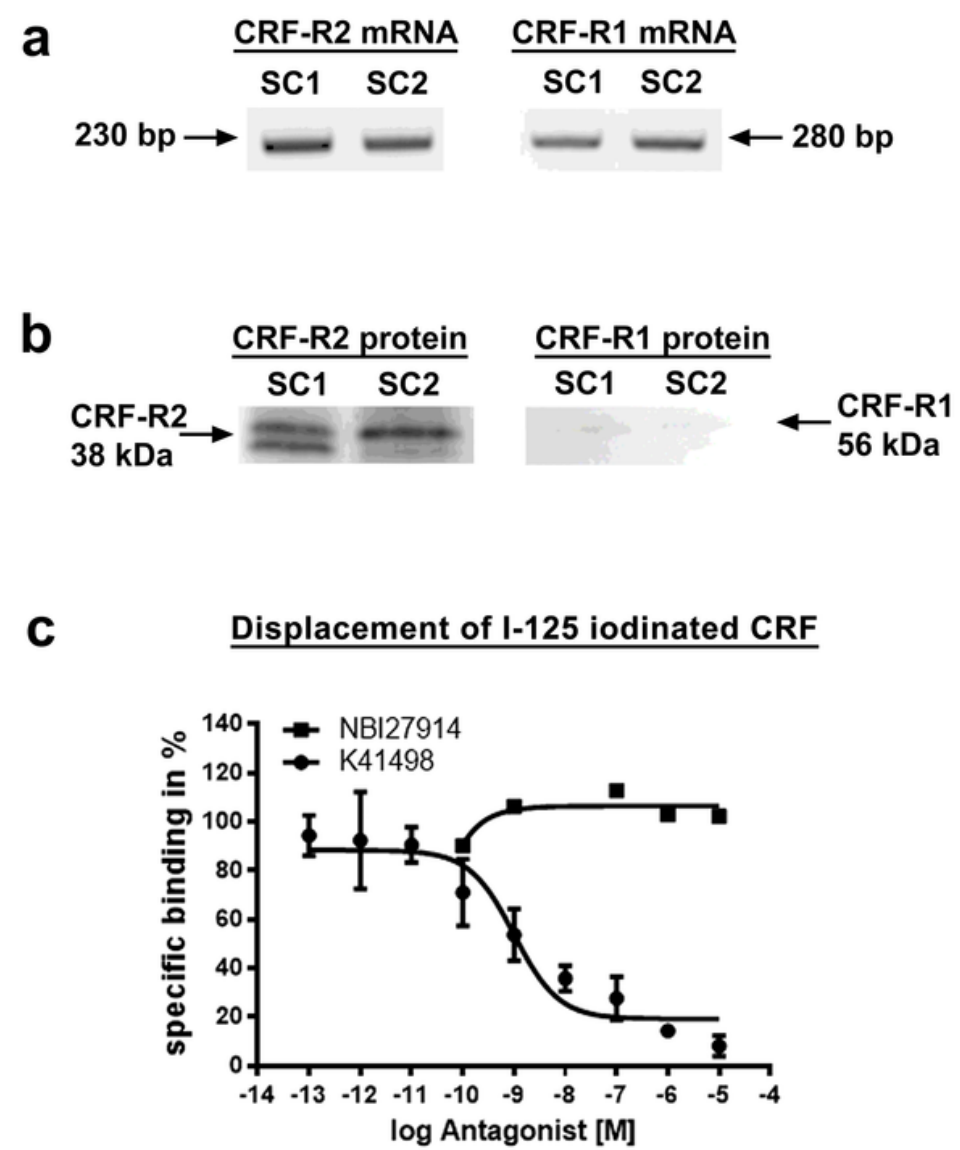

\section{Figure 1}

Demonstration of CRF-R1 and CRF-R2 mRNA and protein as well as specific binding sites in the dorsal part of the spinal cord. a) RNA extraction from the dorsal part of the L4-L5 spinal cord, implementation of conventional PCR using specific primer pairs for CRF-R1 and CRF-R2, and subsequent visualization on a $2 \%$ agarose gel provided specific PCR products for the expression of CRF-R1 (280 bp) and CRF-R2 (230 bp) mRNA. b) Western blot analysis of rat L4-L5 spinal cord using specific antibodies against CRF-R1 and CRF-R2 revealed protein bands at the expected molecular weight of $56 \mathrm{kDa}$ for CRF-R1 and $38 \mathrm{kDa}$ for CRF-R2. Although the same amount of protein was loaded $(20 \mu \mathrm{g})$ onto the gel, the protein band of CRFR2 was much more prominent than that of CRF-R1. c) Displacement of [125J]-CRF- binding by unlabeled CRF-R1- (NBI35965) and CRF-R2- (K41498) selective ligands shows clearly identifiable displacement of [125J]-CRF-binding with increasing concentrations of the CRF-R2-selective antagonist K41498 (IC50=500 
pmol), however, a lack of displacement by the CRF-R1 selective antagonist NBI35965. The curves are fits to a single-site inhibition equation. Data points $(n=8)$ represent means \pm s.e.m.
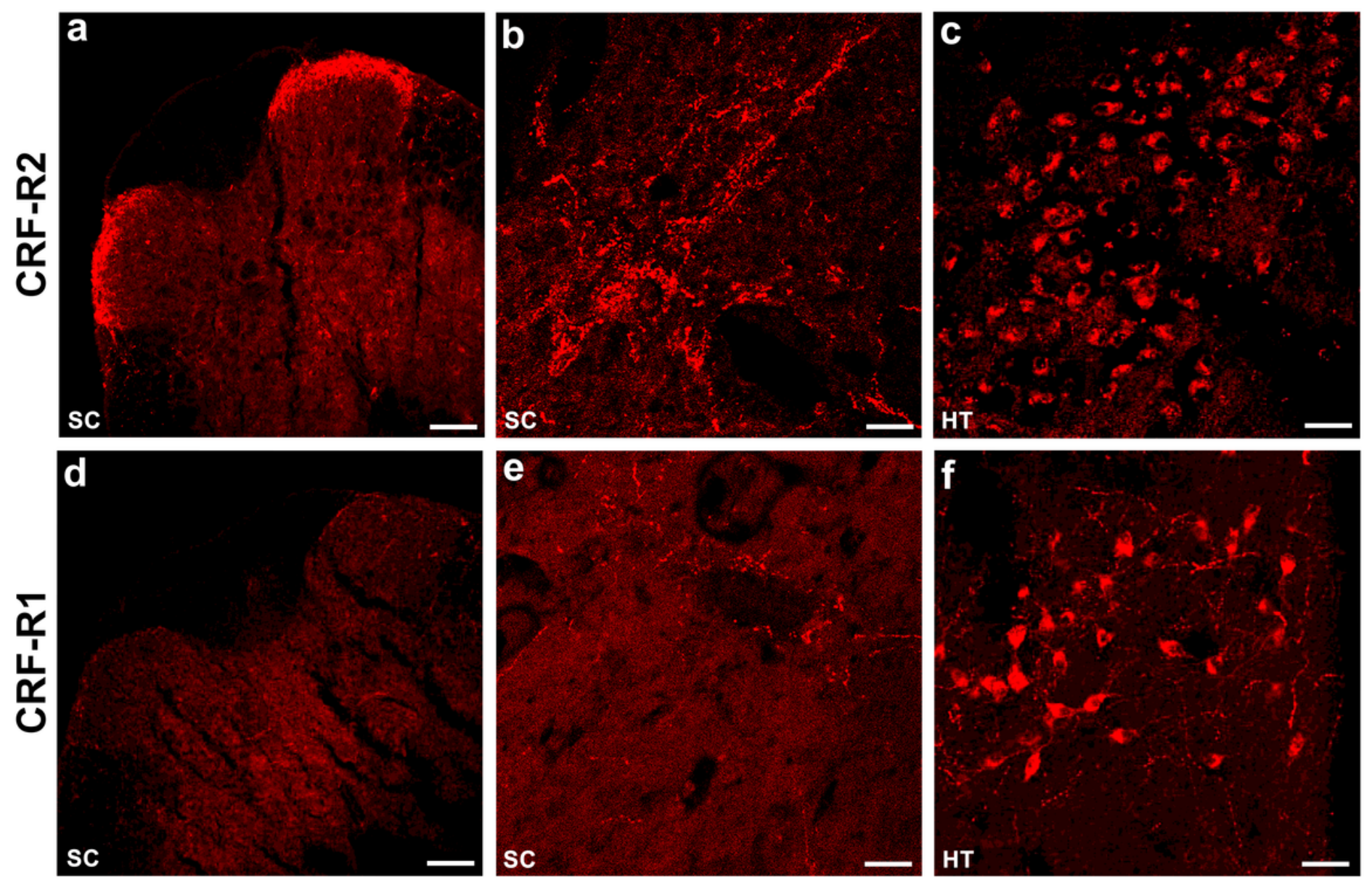

\section{Figure 2}

Immunofluorescence staining of CRF-R2 (a-c) and CRF-R1 (d-f) in the superficial laminae of the rat spinal dorsal horn as well as the brain. a-c) Immunohistochemical staining of the dorsal horn of the spinal cord $(a, b)$ and of the hypothalamus of the brain (c) with the polyclonal rabbit anti-CRF-R2 antibody (Texas red fluorescence). Note specific CRF-R2 immunoreactivity in Rexed laminae I and II of the spinal dorsal horn (a) and in the immediate vicinity of the central canal (b), an area receiving descending projections from supraspinal nuclei. CRF-R2 immunoreactivity was also identified in neurons of the hypothalamus (c). d-f) Immunohistochemical staining of the dorsal horn of the spinal cord $(d, e)$ and of the hypothalamus of the brain (f) with the polyclonal rabbit anti-CRF-R1 antibody (Texas red fluorescence). In contrast to CRF-R2, CRF-R1 immunoreactivity was not identified in the spinal dorsal horn (d) and only scarce around the spinal central canal (e), whereas CRF-R1 was abundantly shown in neurons of the hypothalamus (f). Bar $=40 \mu \mathrm{m}(\mathrm{A}, \mathrm{D}), \mathrm{Bar}=20 \mu \mathrm{m}(\mathrm{B}, \mathrm{C}, \mathrm{E}, \mathrm{F})$. 
a

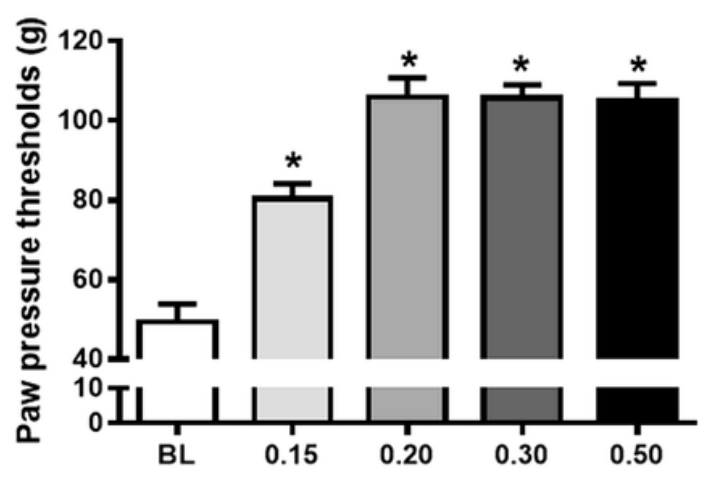

i.t. Corticotropin-Relasing Factor ( $\mu \mathrm{mol})$ b

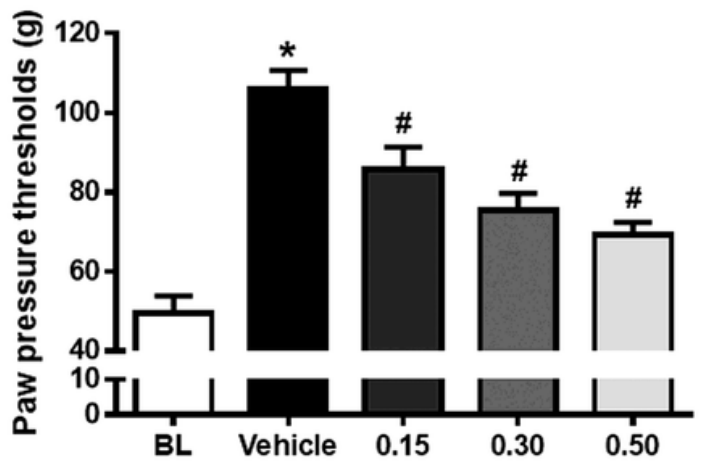

i.t. CRF (0.2 $\mu \mathrm{mol})+$ i.t. K41498 ( $\mu \mathrm{mol})$

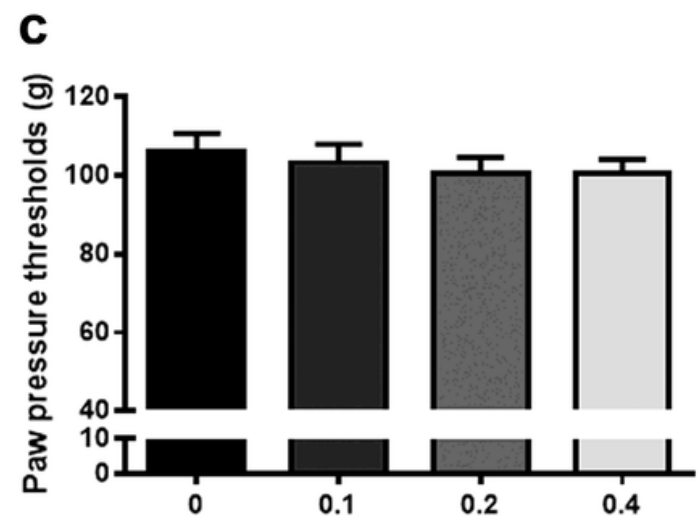

i.t. $\operatorname{CRF}(0.2 \mu \mathrm{mol})+$ i.t. $\mathrm{NBI}(\mu \mathrm{mol})$

\section{Figure 3}

Antagonism of antinociceptive effects of i.t CRF by CRF-R2 (K41498) but not CRF-R1 (NBI35965) antagonist. In Wistar rats with four days FCA hindpaw inflammation, effects of intrathecal (i.t) injections of CRF on nociceptive paw pressure thresholds (PPT) were measured by algesiometry. a) Intrathecal injections of CRF $(0.15,0.2,0.3,0.5 \mu \mathrm{mol})$ significantly increased PPT in a dose-dependent manner $(P<0.001$, one-way ANOVA and post-hoc Dunnett's test, *indicates significant differences from 0 , i.e. vehicle treatment). Data points $(n=6)$ represent means $\pm S D$. b) Dose-dependent antagonism of i.t. CRF's $(0.2 \mu \mathrm{mol})$ antinociception by co-administered CRF-R2 antagonist K41498 $(0.15,0.3,0.5 \mu \mathrm{mol})$ was significant $(P<0.001$, one-way ANOVA and post-hoc Dunnett's test, *indicates significant differences from 0 , i.e. vehicle treatment; \#indicates significant differences from CRF $0.2 \mu \mathrm{mol}+$ vehicle). Data points $(n=6)$ represent means \pm SD. c) Intrathecal injection of $0.2 \mu$ mol CRF significantly increased PPT compared to vehicle $(P<0.001$, one-way ANOVA and post-hoc Dunnett's test, *indicates significant differences from 0 , i.e. vehicle treatment); however, increasing doses of the i.t. CRF-R1 antagonist NBI35965 $(0.15,0.2$, $0.4 \mu \mathrm{mol})$ did not antagonize CRF's $(0.2 \mu \mathrm{mol})$ antinociception $(P>0.05$, one-way ANOVA). Data points $(n=6)$ represent means $\pm S D$. 

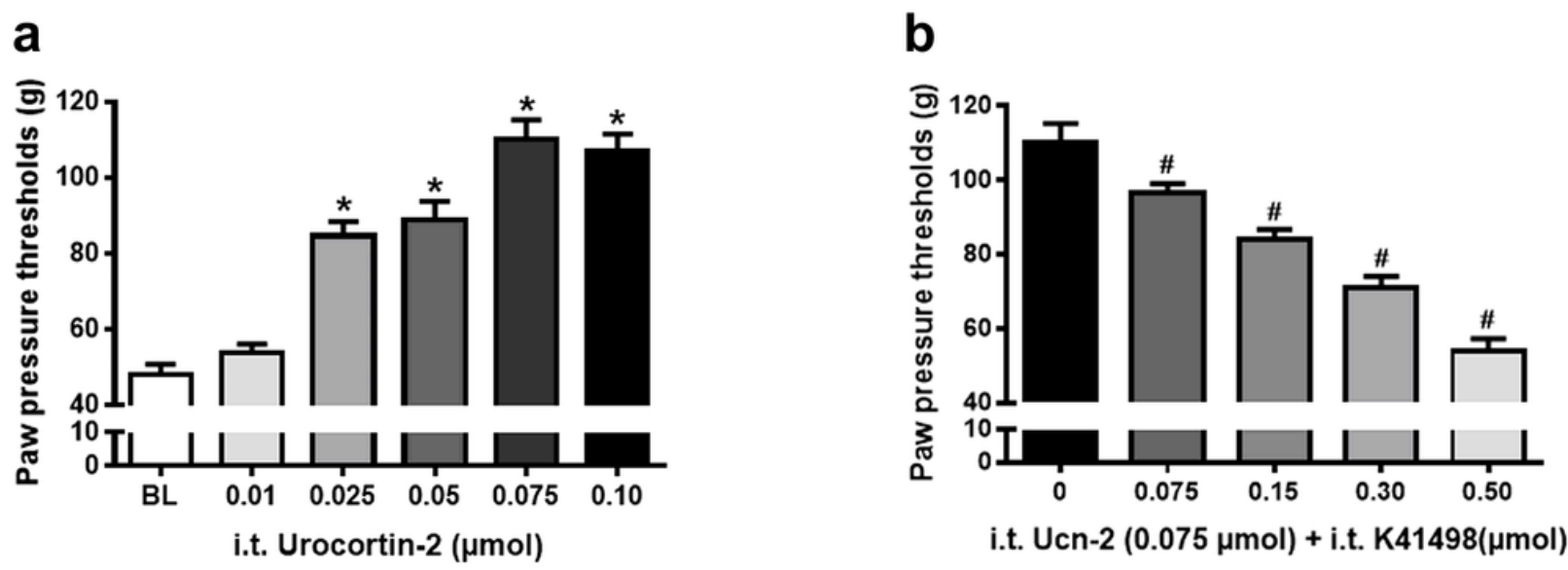

\section{Figure 4}

Antinociceptive effects of the i.t. CRF-R2 agonist Ucn-2 and its antagonism by the CRF-R2 selective antagonist (K41498). In Wistar rats with four days FCA hindpaw inflammation, effects of intrathecal (i.t.) injections of the CRF-R2 agonist Ucn-2 on nociceptive paw pressure thresholds (PPT) were measured by algesiometry. a) Intrathecal injections of the CRF-R2 agonist Ucn-2 significantly increased PPT in a dosedependent manner $(P<0.001$, one-way ANOVA and post-hoc Dunnett's test, *indicates significant differences from 0 , i.e. vehicle treatment). Data points $(n=6)$ represent means $\pm S D$. b) Intrathecal injection of $0.075 \mu \mathrm{mol}$ UCN-2 significantly increased PPT compared to vehicle $(P<0.001$, one-way ANOVA and post-hoc Dunnett's test, *indicates significant differences from 0, i.e. vehicle treatment); however, dosedependent antagonism of i.t. Ucn-2 $(0.075 \mu \mathrm{mol})$ antinociception by co-administered CRF-R2 antagonist K41498 $(0.075,0.15,0.3,0.5 \mu \mathrm{mol})$ was significant $(P<0.001$, one-way ANOVA and post-hoc Dunnett's test, \#indicates significant differences from 0 , i.e. vehicle treatment). Data points $(n=6)$ represent means $\pm S D$. 

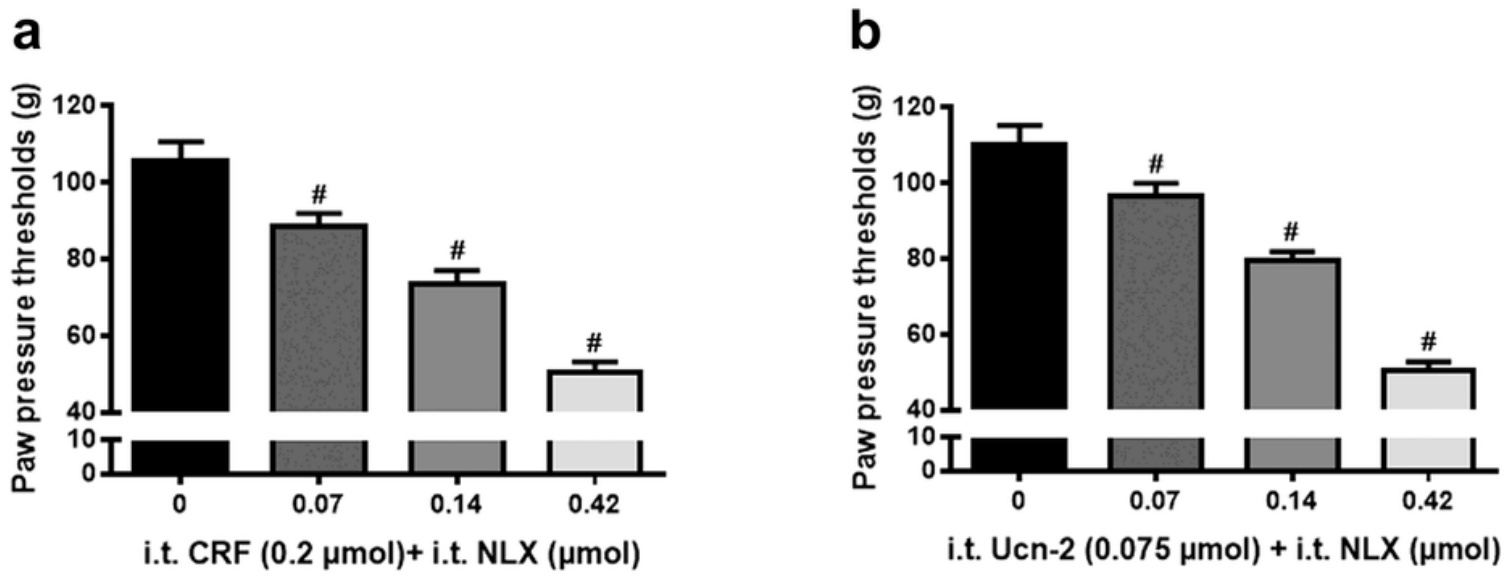

\section{Figure 5}

Attenuation of the antinociceptive effects of i.t. CRF and CRF-R2 agonist Ucn-2 by the opioid receptor antagonist naloxone. In Wistar rats with four days FCA hindpaw inflammation, effects of i.t. coadministration of the opioid receptor antagonist naloxone with CRF or CRF-R2 agonist Ucn-2 on nociceptive paw pressure thresholds (PPT) were measured by algesiometry. a) Dose-dependent attenuation of i.t. CRF's $(0.2 \mu \mathrm{mol})$ antinociception by co-administered opioid receptor antagonist naloxone $(0.07,0.14,0.42 \mu \mathrm{mol})$ was significant $(P<0.001$, one-way ANOVA and post-hoc Dunnett's test, \#indicates significant differences from CRF $(0.2 \mu \mathrm{mol})+$ vehicle $)$. Data points $(n=6)$ represent means $\pm S D$.

b) Dose-dependent attenuation of i.t. CRF-R2 agonist Ucn-2 $(0.075 \mu \mathrm{mol})$ antinociception by coadministered opioid receptor antagonist naloxone $(0.07,0.14,0.42 \mu \mathrm{mol})$ was significant $(P<0.001$, oneway ANOVA and post-hoc Dunnett's test, \#indicates significant differences from UCN-2 (0.075 $\mu \mathrm{mol})$ indicates significant differences from 0 , i.e. vehicle treatment). Data points $(n=6)$ represent means $\pm S D$. 

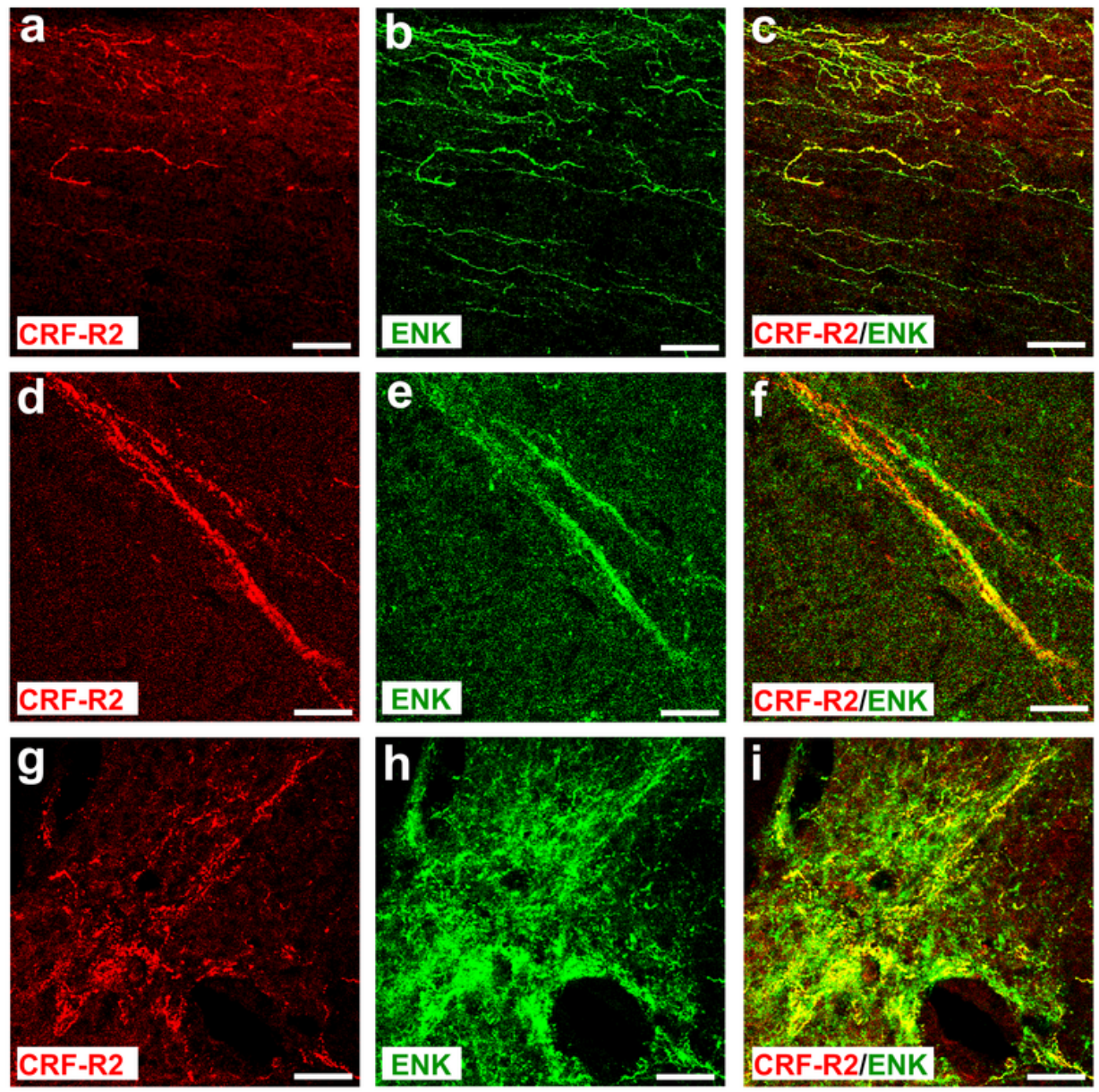

\section{Figure 6}

Double immunofluorescence staining of CRF-R2 $(a, d, g)$ and ENK $(b, e, h)$ in the rat L4-L5 spinal cord. $a, b$, c) Parasagittal sections of L4-L5 spinal cord of the rat show a network of CRF-R2-immunoreactive fibres overlapping with ENK and extending through the superficial laminae of the dorsal horn of the lumber spinal cord. Some fibers express only ENK. (d-i) Double immunofluorescence staining of coronal sections of spinal cord of the rat showing that CRF-R2-immunoreactive fibers overlap with ENK. Some fibers express ENK only. Bar $=20 \mu \mathrm{m}$ 

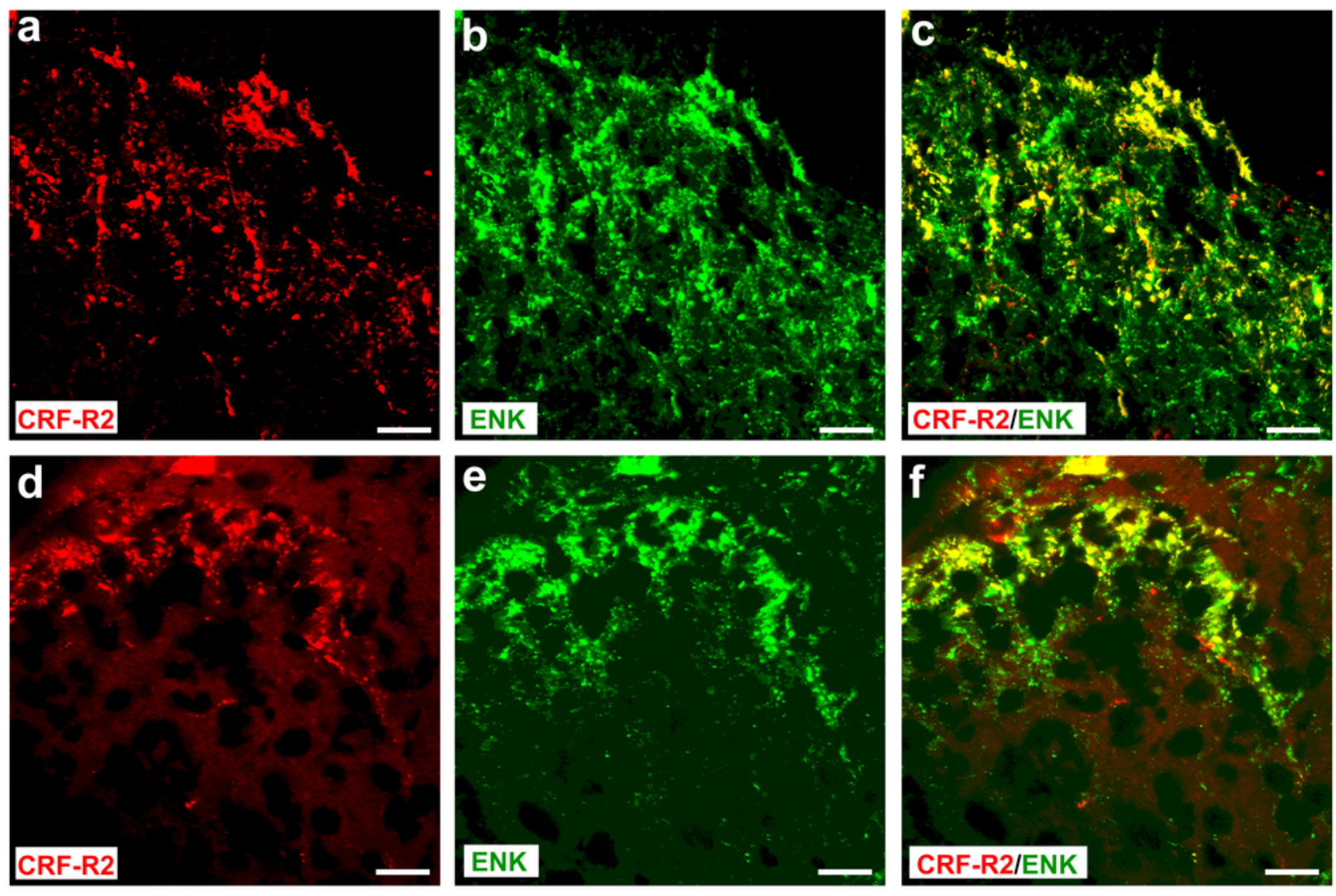

\section{Figure 7}

Double immunofluorescence staining of CRF-R2 $(a, d)$ and ENK $(b, e)$, in the rat superficial laminae of the L4-L5 spinal dorsal horn. a-f) show that most of CRF-R2-immunoreactive fibres express ENK in coronal sections of the L4-L5 spinal dorsal horn of Wistar rats, but few fibers contain CRF-R2 (Texas red fluorescence) or ENK (FITC green fluorescence) only. Bar $=20 \mu \mathrm{m}$. 

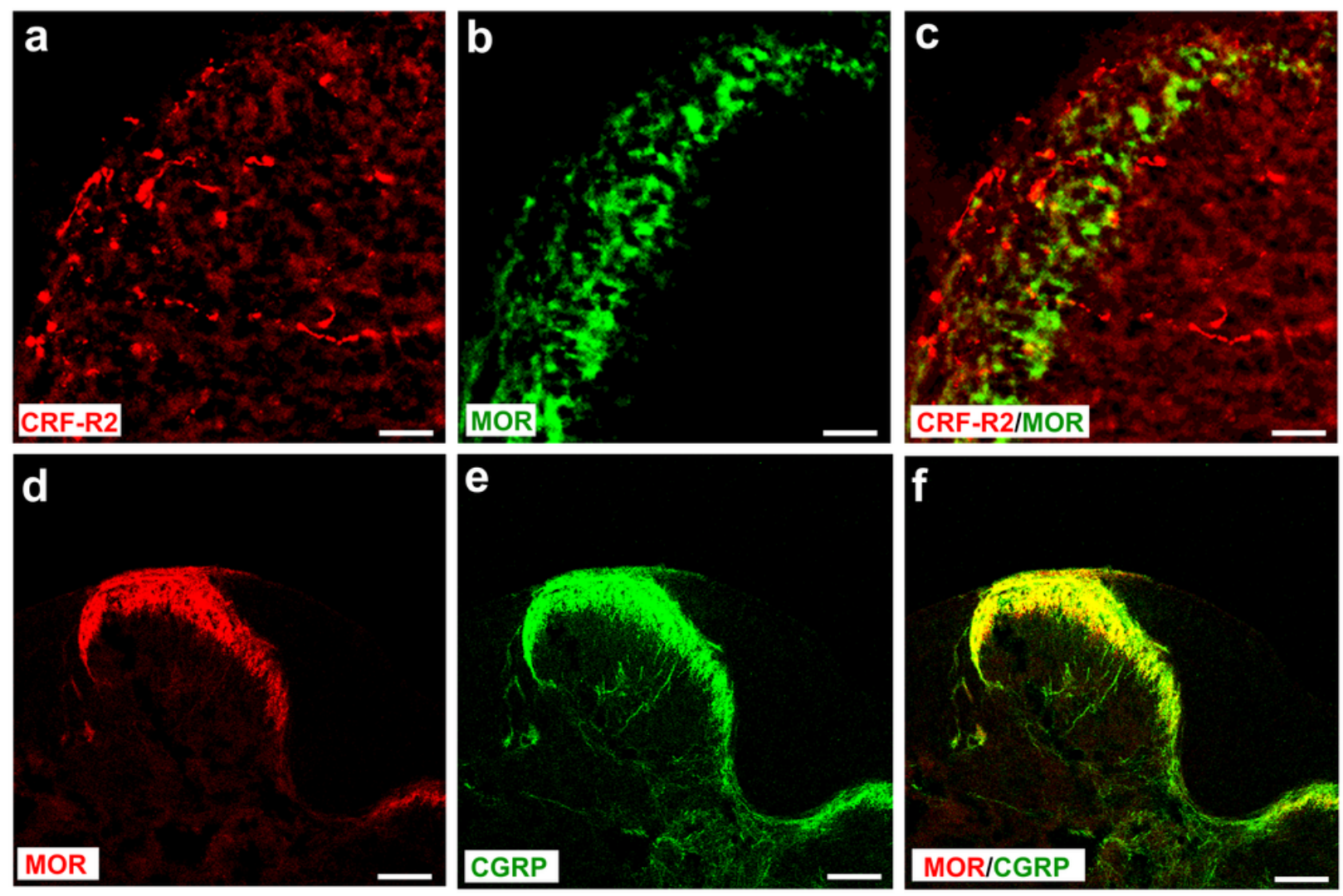

\section{Figure 8}

Double immunofluorescence staining of CRF-R2 (a) with MOR (b) or MOR (d) with CGRP (e) in the rat superficial laminae of the L4-L5 spinal dorsal horn. A-C) show in coronal sections of the L4-L5 spinal dorsal horn that most of CRF-R2-immunorective fibres (Texas red fluorescence) $(a, c)$ do not express MOR (FITC green fluorescence) (b, c); d-f) however, MOR-immunorecative fibres (Texas red fluorescence) (d) overlap with CGRP (FITC green fluorescence) (e), a neuronal marker of incoming nociceptive nerve fibres. $\mathrm{Bar}=20 \mu \mathrm{m}$ 